\title{
Synthesis of High cis-1,4-BR with Neodymium for the Manufacture of Tires
}

\author{
Maria Leonor Méndez-Hernández, ${ }^{1}$ José Luis Rivera-Armenta, ${ }^{1}$ Ulises Páramo-García, ${ }^{1}$ \\ Sergio Corona Galvan, ${ }^{2}$ Ricardo García-Alamilla, ${ }^{1}$ and Beatriz Adriana Salazar-Cruz ${ }^{1}$ \\ ${ }^{1}$ División de Estudios de Posgrado e Investigación, Instituto Tecnológico de Ciudad Madero, J. Rosas y J. Urueta S/N, \\ Colonia Los Mangos, 89440 Cuidad Madero, TAMPS, Mexico \\ ${ }^{2}$ Repsol YPF Technology Center, Carretera de Extremadura, Km 18, Móstoles, 28931 Madrid, Spain
}

Correspondence should be addressed to José Luis Rivera-Armenta; jlriveraarmenta@itcm.edu.mx

Received 13 October 2015; Revised 6 February 2016; Accepted 23 February 2016

Academic Editor: Atsushi Sudo

Copyright ( 2016 Maria Leonor Méndez-Hernández et al. This is an open access article distributed under the Creative Commons Attribution License, which permits unrestricted use, distribution, and reproduction in any medium, provided the original work is properly cited.

\begin{abstract}
The salt of neodymium has been widely used in industrial polymerization of 1,3-butadiene. We used the ternary catalytic system neodymium versatate/diethylaluminum chloride/triisobutylaluminum $\left(\mathrm{NdV}_{3} / \mathrm{DEAC} / \mathrm{TIBA}\right)$ with $0.5 \mathrm{mM} \mathrm{NdV} / 100 \mathrm{~g} \mathrm{Bd}$, $\mathrm{NdV}_{3}: \mathrm{DEAC}=1: 9 \mathrm{~mol}: \mathrm{mol}$, and TIBA $=25,50,100$, and $200 \mathrm{mM}$. The number-average molecular weight $(\mathrm{Mn})$, weight-average molecular weight (Mw), and polydispersity index (PDI) were analyzed by GPC; the rheological properties were analyzed by DMA. The formulations were prepared with carbon black (IRB6) as reinforcing filler and the mechanical properties were compared to behavior of the different elastomeric compounds. The elastomeric compounds were characterized by their rheological properties, tensile strength, abrasion resistance, tear strength, permanent set, resilience, and fatigue properties. The high cis-1,4 polybutadiene (high cis-1,4-BR) was obtained with a percentage of cis-1,4 $\geq 97 \%$. The weight-average molecular weight $(\mathrm{Mw})$ was from $150 \times 10^{3}$ to $900 \times 10^{3} \mathrm{~g} / \mathrm{mol}$ and polydispersity index (PDI) was from 3.1 to 5.1. This work is based on evaluation of the effect of the catalyst system on the final properties of the synthesized polybutadiene.
\end{abstract}

\section{Introduction}

The neodymium catalyst causes high catalytic activity during the polymerization of dienes; however good control has not been achieved with regard to molecular weight and molecular weight distribution, which is attributed to the multiple active sites present in this catalyst. The advantages of using ternary catalytic systems are to provide a homogeneous catalyst soluble in nonpolar solvents, to give polybutadiene having low gel content, and to decrease viscosity to provide a quantitative measure of the catalyst $[1,2]$. The catalysts based on neodymium have many advantages over other catalysts used for the polymerization of cis-polybutadiene. They are more active in aliphatic solvents than in aromatic solvents. They are free of cationic activity and essentially give linear polymers with high contents of cis-1,4-BR $[3,4]$. The cis-polybutadiene obtained with these catalysts exhibits excellent elastomeric properties and is particularly suitable for use in tires $[5,6]$. The alkyl aluminum is capable of activating the catalyst for producing high cis-1,4-BR with different molecular weight distributions depending on the polymerization parameters and methods used to prepare the catalyst $[7,8]$. High cis-1,4-BR is an elastomer essential for tire manufacturing because of the advantages obtained by adding this substance to styrene-butadiene rubber (SBR) and polyisoprene, such as outstanding low wear resistance, rolling resistance, high elasticity even at low temperatures, high flexibility to cracking, fatigue resistance, and improved adhesion to metals. This behavior is important for use in many parts of radial and bias tires [9-11]. The global consumption and production of high cis-1,4-BR in 2010 were approximately 2.8 million metric tons per year and an increase of $4.0 \%$ is estimated per year from 2010 to 2015. A lot of this annual production is used in the tire industry $[6,12,13]$. The tire of an automobile contains about twelve components, whereas a 
truck tire has approximately twenty components. The rubbers used in the tire industry market are natural rubber (NR), styrene-butadiene rubber (SBR), polybutadiene rubber (BR), and ethylene propylene diene monomer (EPDM) rubber $[11,14]$. The high stereoregularity provides excellent dynamic mechanical properties, especially higher tensile strength, lower heat buildup, and better abrasion resistance [15-17].

\section{Experimental}

2.1. Materials. The following materials are used: neodymium versatate $\left(\mathrm{NdV}_{3}\right)$ from Rhône-Poulenc (Rhodia) 1.5\% (w/w) in cyclohexane, $\mathrm{Al} \mathrm{Et}{ }_{2} \mathrm{Cl}$ (DEAC) $(1.0 \mathrm{M}$ in hexane, Aldrich Chemicals) and $\mathrm{Al}(\mathrm{i}-\mathrm{Bu})_{3}$ (TIBA) $(1.0 \mathrm{M}$ in hexane, Aldrich Chemicals), 1,3-butadiene and cyclohexane both from Dynasol Elastomers that were previously purified through columns packed with alumina and molecular sieve system installed in reactors to inhibit and eliminate moisture, respectively, isopropyl alcohol (terminate reaction), and Irganox 1076/TNPP (antioxidants).

2.2. Catalyst Preparation: $N d V_{3}$. The neodymium salt $(1.5 \%$ $\mathrm{w} / \mathrm{w})$ is dissolved in cyclohexane with magnetic stirring at room temperature under inert atmosphere. The catalyst $\mathrm{NdV}_{3}$ is activated by adding cocatalysts in the following order: diethylaluminum chloride (DEAC) and triisobutylaluminum (TIBA).

2.3. Synthesis of High cis-1,4-BR. The polymerization reactions did not happen when the relationship from $0.5 \mathrm{mM}$ $\mathrm{NdV}_{3} / 100 \mathrm{~g} \mathrm{Bd}\left(\mathrm{NdV}_{3}\right.$ : DEAC) was equal to or less than $1: 5 \mathrm{~mol}: \mathrm{mol}$. This was attributed to the presence of poisons in the reaction system. Cyclohexane (308 g), 1,3-butadiene $(31 \mathrm{~g})$, and the activated $\mathrm{Nd}$ catalyst $\left(0.5 \mathrm{mM} \mathrm{NdV}_{3} / 100 \mathrm{~g}\right.$ Bd) $\left(\mathrm{NdV}_{3}: \mathrm{DEAC}=1: 9 \mathrm{~mol}: \mathrm{mol}\right.$ and $\mathrm{TIBA}=25,50,100$, and $200 \mathrm{mM}$ ) were added to a $900 \mathrm{~mL}$ pressure glass reactor under a nitrogen atmosphere and reacted at 35 to $70^{\circ} \mathrm{C}$ for $40 \mathrm{~min}$. The resulting polybutadiene was stabilized with Irganox 1076/TNPP and terminated by isopropyl alcohol.

2.4. Polymer Characterization. The monomer conversion was determined by gravimetric method. The number-average molecular weight $(\mathrm{Mn})$, the weight-average molecular weight $(\mathrm{Mw})$, and polydispersity index (PDI) were determined by liquid chromatography equipped with a light scattering (LS) detector. The increased rate of refraction $(d n / d c)$ was obtained experimentally in a refractometer, the operating temperature was $40^{\circ} \mathrm{C}$, and $\mathrm{K} 5$ quartz cell was used; in all cases the measurements were made at $480 \mathrm{~nm}$ in THF. The polybutadiene used as a standard for determining microstructure by infrared spectroscopy was characterized by ${ }^{1} \mathrm{H}$ NMR. ${ }^{1} \mathrm{H}$ NMR were carried out in a Bruker DRX 500 spectrometer. Spectra were obtained by using $5 \mathrm{~mm}$ tubes, $\mathrm{CDCl}_{3}$ (solvent and lock signal), and TMS (reference), at room temperature $\left(25^{\circ} \mathrm{C}\right)$. The samples were diluted in $\mathrm{CDCl}_{3}(0.5 \% \mathrm{v} / \mathrm{v})$, obtaining solutions of $30 \% \mathrm{v} / \mathrm{v}$ final concentration. The acquisition conditions were pulse duration, $9.2 \mu \mathrm{s}\left(90^{\circ}\right)$, with $6 \mathrm{~dB}$ attenuation; acquisition time, $2.9 \mathrm{~s}$; interval between pulses, $1.5 \mathrm{~s}$; and number of scans, 64 . The IR spectra of the samples solution were obtained between 4000 and $400 \mathrm{~cm}^{-1}$ in a $\mathrm{KBr}$ cell with FTIR spectrometer (Nicolet Magna IR 560). A minimum of 16 scans was signal averaged with a resolution of $2 \mathrm{~cm}^{-1}$. The Mooney viscosity of the polymers and their compounds in melt state was measured according to ASTM D-1646 at $100^{\circ} \mathrm{C}$ in Alpha Technologies viscometer (model MV2000). For vulcanization of compound, samples of $10-15 \mathrm{~g}$ were placed between two $12 \times 12$ stainless steel plates preheated to the temperature studied. The plates were then inserted into the compression compartment of a Carver Press Machine (Carver Inc.) model 3710 (25 ton capacity) with heating/cooling platens. Physical properties of the compounds were measured with a universal testing machine (Instron 5565). The mixed compounds of tires were made in Brabender plastograph manufactured by $\mathrm{M} / \mathrm{S}$ Brabender OHG, Duisburg; temperature of mixing chamber was $120^{\circ} \mathrm{C}$, time of mastication was $10 \mathrm{~min}$, and rotor speed was $60 \mathrm{rpm}$. The resilience test was carried out according to ASTM D-2632 and ASTM D-3182 at $25^{\circ} \mathrm{C}$ in a resiliometer (model PF 005). The Dynamic Mechanical Analysis (DMA) measures the response of a given material to an oscillatory deformation (here in torsion mode) as a function of temperature. The rheometry was carried out with a PAAR Physica UDS 200 rheometer. The estimation of abrasion resistance was run according to DIN 53516 at $23^{\circ} \mathrm{C}$ in Muver equipment model 5057. Shore A hardness was estimated according to DIN 53505 in a Brasser durometer at $23^{\circ} \mathrm{C}$.

\section{Results and Discussion}

3.1. Effect of Reaction Temperature and Concentration TIBA on the Monomer Conversion, Polymer Molecular Weight, and Microstructure. The criterion that the molecular weight increases linearly with conversion has been frequently used to mean a living polymerization is controlled [4]. The influence of the initial reaction temperature and the addition of alkyl aluminum play an important role in monomer conversion and polymer molecular weight. As the level of TIBA goes from $25 \mathrm{mM}$ to $200 \mathrm{mM}$, conversion increases, not the molecular weight of the high cis-1,4-BR. The activity of the catalyst system is enhanced when the level of TIBA increases, resembling the behavior developed when the catalyst is increased, and acts as transfer agent chain having greater conversion net effect by generating more active sites and a decrease in molecular weight to frequently generate new species. To this end, results of the evolution of molecular weight with conversion are discussed, for determining whether the polymerizations of 1,3-butadiene with the neodymium catalyst can be considered as living (see Table 1). The percentage of conversion of high cis-1,4-BR with ternary catalyst system is shown in Figure $1\left(0.5 \mathrm{mM} \mathrm{NdV}_{3} / 100 \mathrm{~g} \mathrm{Bd}, \mathrm{NdV}_{3}\right.$ : DEAC $=$ $1: 9 \mathrm{~mol}: \mathrm{mol}$, and TIBA $=25,50,100$, and $200 \mathrm{mM}$ ).

Based on the results obtained with respect to polymer conversion, it can be shown that the combination of reaction temperature and catalyst system which provide greater monomer conversion ( $\cong 96 \%)$ during a 5 -minute reaction (minus residence time) is what was obtained at $70^{\circ} \mathrm{C}$ with 
TABLE 1: Molecular weight and conversion of high cis-1,4-BR.

\begin{tabular}{|c|c|c|c|c|c|c|c|c|c|c|c|c|}
\hline \multirow{3}{*}{$\mathrm{T}_{o}{ }^{\circ} \mathrm{C}$} & \multicolumn{12}{|c|}{$0.5 \mathrm{mM} \mathrm{NdV}_{3} / 100 \mathrm{~g} \mathrm{Bd}, \mathrm{NdV}_{3}: \mathrm{DEAC}=1: 9 \mathrm{~mol}: \mathrm{mol}, \mathrm{TIBA} \mathrm{mM}$} \\
\hline & \multicolumn{3}{|c|}{$[25]$} & \multicolumn{3}{|c|}{$[50]$} & \multicolumn{3}{|c|}{$[100]$} & \multicolumn{3}{|c|}{ [200] } \\
\hline & $\%$ conv. & $\mathrm{Mw} \times 10^{3}$ & IP & $\%$ conv. & $\mathrm{Mw} \times 10^{3}$ & IP & $\%$ conv. & $\mathrm{Mw} \times 10^{3}$ & IP & $\%$ conv. & $\mathrm{Mw} \times 10^{3}$ & IP \\
\hline 35 & 73.7 & 500.6 & 3.2 & 80.1 & 376.4 & 2.8 & 88.1 & 284.4 & 2.0 & 90.3 & 197 & 3.5 \\
\hline 45 & 77.8 & 675.4 & 2.5 & 83.9 & 438 & 2.6 & 92 & 297.7 & 3.1 & 92.3 & 249.1 & 3.0 \\
\hline 55 & 82.3 & 811.4 & 1.8 & 85.7 & 572.6 & 1.5 & 95.3 & 314.2 & 2.4 & 94.1 & 307.6 & 6.5 \\
\hline 70 & 83.1 & 855.9 & 2.6 & 86.3 & 580.5 & 1.9 & 96 & 412.8 & 1.6 & 96.3 & 317 & 6.9 \\
\hline
\end{tabular}

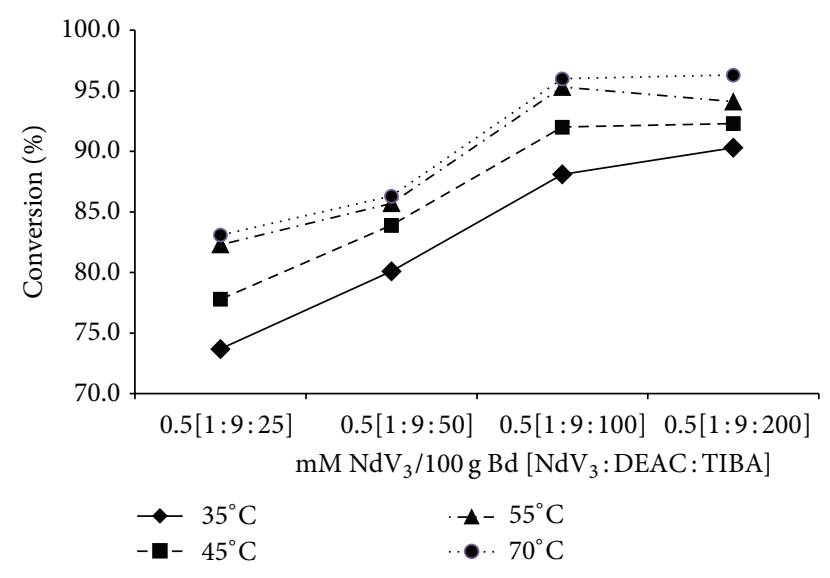

FIGURE 1: Effect of TIBA and the reaction temperature on monomer conversion.

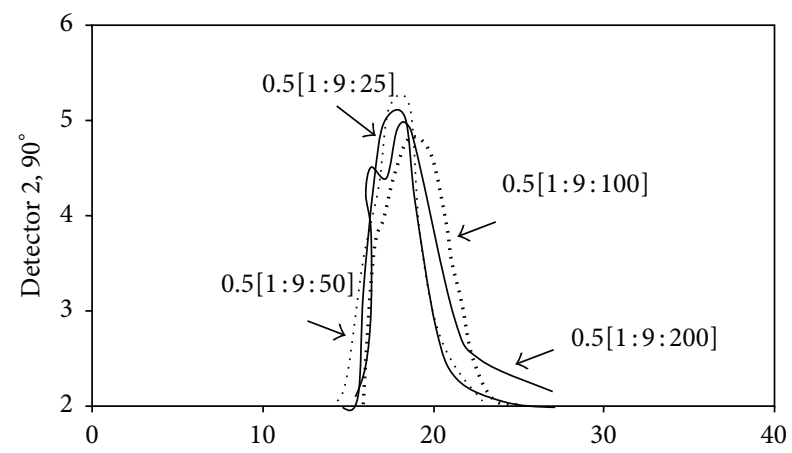

Figure 2: Effect of TIBA on weight-average molecular weight.

TIBA $\geq 100 \mathrm{mM}$. As reported by [6] when neodymium is used as a catalyst, it is possible to achieve complete conversion of the monomer and obtain a high cis-1,4-BR with low gel content.

The effect of TIBA concentration on an average molecular weight of high cis-1,4-BR, carried out at $70^{\circ} \mathrm{C}$ with $0.5 \mathrm{mM}$ $\mathrm{NdV}_{3} / 100 \mathrm{~g} \mathrm{Bd}, \mathrm{NdV}_{3}: \mathrm{DEAC}=1: 9 \mathrm{~mol}: \mathrm{mol}$, and $\mathrm{TIBA}=$ $25,50,100$, and 200 mmoles, is shown in Figure 2 . The polymerization times for all reactions were $40 \mathrm{~min} . \mathrm{NdV}_{3}$, when activated with TIBA, was catalytically effective for polymerizing 1,3-butadiene, being capable of producing a highly linear, high molecular weight and a monomodal distribution of polymer molecular weight, indicating that a uniform behavior center was active.

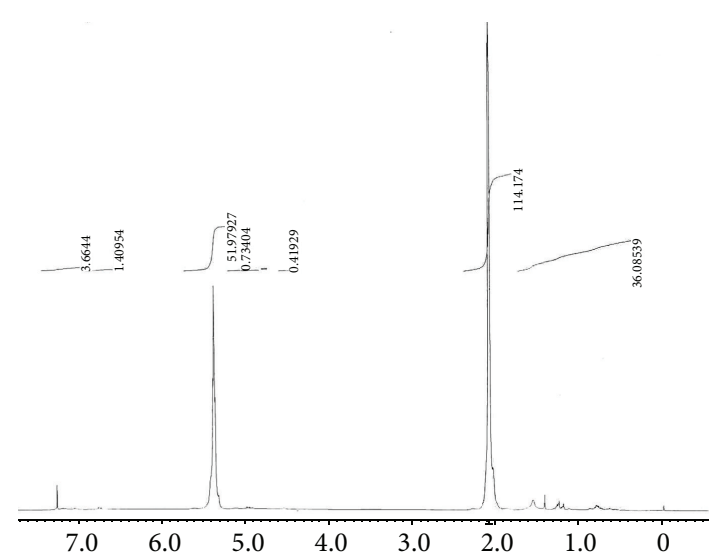

FIGURE 3: Spectrum ${ }^{1} \mathrm{H}$ NMR of high cis-1,4-BR synthesized with $0.3 \mathrm{~mm} \mathrm{NdV}_{3} / 100 \mathrm{~g} \mathrm{Bd}, \mathrm{NdV}_{3}:$ DEAC $=1: 9 \mathrm{~mol}: \mathrm{mol}$, and TIBA $=$ $200 \mathrm{mM}$.

Table 1 shows the result of evolution of weight-average molecular weight (Mw) and polydispersity index (DPI) with conversion at different initial reaction temperatures, using $0.5 \mathrm{mM} \mathrm{NdV}_{3} / 100 \mathrm{~g} \mathrm{Bd}, \mathrm{NdV}_{3}: \mathrm{DEAC}=1: 9 \mathrm{~mol}: \mathrm{mol}$, and $\mathrm{TIBA}=25,50,100$, and $200 \mathrm{mM}$. An interesting effect is that, at $35^{\circ} \mathrm{C}$, while the level of TIBA goes from $25 \mathrm{mM}$ to $200 \mathrm{mM}$, the conversion increases, although the molecular weight of the product decreases in absolute terms with respect to the molecular weights observed when smaller amounts of TIBA were used. The same behavior occurs when the temperature is increased from $45^{\circ} \mathrm{C}$ to $70^{\circ} \mathrm{C}$. This effect is probably related to the fact that the TIBA catalyst activity increases and acts like a chain transfer agent, with the net effect being greater conversion by generating more active centers and decreasing molecular weight, often generating new species.

The spectrum of ${ }^{1} \mathrm{H}$ NMR of high cis-1,4-BR, synthesized with $0.3 \mathrm{mM} \mathrm{NdV}_{3} / 100 \mathrm{~g} \mathrm{Bd}, \mathrm{NdV}_{3}: \mathrm{DEAC}=1: 9 \mathrm{~mol}: \mathrm{mol}$, and TIBA $=200 \mathrm{mM}$, is shown in Figure 3. This spectrum was used as a standard for determining the microstructure by IR (FTIR). In spectrum ${ }^{1} \mathrm{H}$ NMR of high cis-1,4-BR, characteristic signals of polybutadiene according to Mochel method were identified [18]. For structure 1,4 cis and trans, in the spectra, a signal at $5.4 \mathrm{ppm}(=\mathrm{CH}-)$ for terminal olefinic protons at 4.9-5.02 ppm $(1,2)$ and for nonterminal olefinic protons $(=\mathrm{CH}-)$ at $5.04 \mathrm{ppm}$ can be identified.

An infrared spectrum of high cis-1,4-BR synthesized with $0.5 \mathrm{mM} \mathrm{NdV}_{3} / 100 \mathrm{~g} \mathrm{Bd}, \mathrm{NdV}_{3}: \mathrm{DEAC}=1: 9 \mathrm{~mol}: \mathrm{mol}$, and 
TABLE 2: Microstructure of high cis-1,4-BR.

\begin{tabular}{|c|c|c|c|c|}
\hline \multirow{3}{*}{$T_{o}{ }^{\circ} \mathrm{C}$} & \multicolumn{4}{|c|}{$0.5 \mathrm{mM} \mathrm{NdV}_{3} / 100 \mathrm{~g} \mathrm{Bd}, \mathrm{NdV}_{3}: \mathrm{DEAC}=1: 9 \mathrm{~mol}: \mathrm{mol}, \mathrm{TIBA} \mathrm{mM}$} \\
\hline & [25] & {$[50]$} & {$[100]$} & [200] \\
\hline & $\%$ cis & $\%$ cis & $\%$ cis & $\%$ cis \\
\hline 35 & 98.6 & 97.8 & 97.9 & 92.5 \\
\hline 45 & 97.6 & 98.2 & 97.3 & 88.0 \\
\hline 55 & 97.8 & 98.1 & 98.3 & 88.0 \\
\hline 70 & 96.7 & 97.6 & 98.0 & 90.8 \\
\hline
\end{tabular}

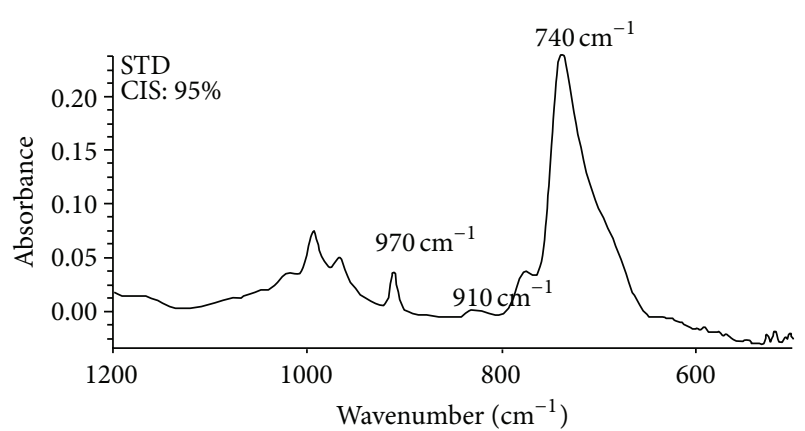

FIGURE 4: Spectrum FTIR of high cis-1,4-BR synthesized with $0.5 \mathrm{mM} \mathrm{NdV} \mathrm{Na}_{3} / 100 \mathrm{~g} \mathrm{Bd}, \mathrm{NdV}_{3}: \mathrm{DEAC}=1: 9 \mathrm{~mol}: \mathrm{mol}$, and TIBA $=200 \mathrm{mM}$.

TIBA $=200 \mathrm{mM}$ used as a reference in determining the content of 1,4-cis units is shown in Figure 4.

Height signals cis $(\mathrm{C}=\mathrm{C})$ at $970 \mathrm{~cm}^{-1}$, vinyl $\left(=\mathrm{CH}_{2}\right)$ at $910 \mathrm{~cm}^{-1}$, and trans $(\mathrm{C}=\mathrm{C})$ at $740 \mathrm{~cm}^{-1}$ were measured and were compared against the same signals of the reference sample. The results of infrared were obtained by comparing the test sample with sample of known composition by proton nuclear magnetic resonance.

Table 2 shows the result of microstructure at different initial reaction temperatures, using $0.5 \mathrm{mM} \mathrm{NdV}_{3} / 100 \mathrm{~g} \mathrm{Bd}$, $\mathrm{NdV}_{3}: \mathrm{DEAC}=1: 9 \mathrm{~mol}: \mathrm{mol}$, and TIBA $=25,50,100$, and $200 \mathrm{mM}$. Polybutadienes with levels of cis-1,4-BR higher than $88 \%$ until $98 \%$ were obtained. These results demonstrate that neodymium versatate in combination with diethylaluminum chloride and TIBA forms a catalyst system capable of producing high levels of polybutadienes having 1,4-cis units.

3.2. Effect of Concentration of TIBA on Mooney Viscosity and Polymer Molecular Weight. The molecular weight, shown in Table 1, was obtained by a light scattering technique which is very effective but difficult to apply, besides being very expensive. With the aim of finding a methodology that could correlate the molecular weights of the products with Mooney viscosity, this parameter is determined using a conventional Mooney viscometer. The Mooney viscosity is a parameter, which indirectly measures the molecular weight of the polymer and is related to the process ability of the product. The Mooney viscosity of polybutadiene synthesized from $35^{\circ} \mathrm{C}$ to $70^{\circ} \mathrm{C}$ using ratios of $0.5 \mathrm{mM} \mathrm{NdV} / 100 \mathrm{~g} \mathrm{Bd}$, $\mathrm{NdV}_{3}: \mathrm{DEAC}=1: 9 \mathrm{~mol}: \mathrm{mol}$, and TIBA $=25,50,100$, and

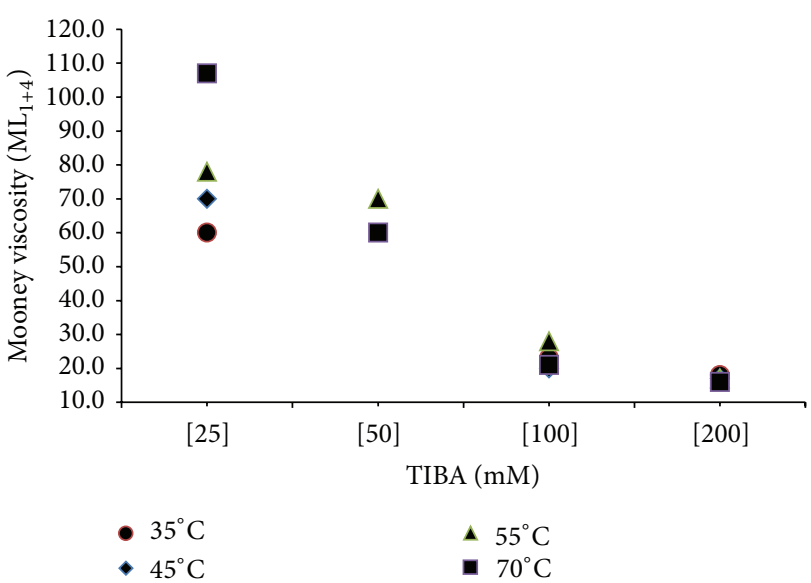

FIgURe 5: Mooney viscosity versus TIBA of high cis-1,4-BR.

$200 \mathrm{mM}$ is shown in Figure 5. The increase in TIBA from 25 to $200 \mathrm{mM}$ results in a reduction in Mooney viscosity from $100 \mathrm{MU}$ to $16 \mathrm{MU}$. This behavior is independent of the initial reaction temperature and is similar to that reported in Section 3.1 which discusses the evolution of molecular weights and conversion with temperature.

The Mooney viscosity shows good correlation with the molecular weight when the high cis-1,4-BR has the same macrostructure regarding the linearity of the macromolecule. As branches, the hydrodynamic volume of the chains decreases, causing a decrease in the Mooney viscosity but not in molecular weight, so it is considered feasible to establish a relationship between the molecular weight and Mooney viscosity to be formed $[19,20]$. The Mooney viscosity behavior versus Mw is shown in Figure 6, where it is evident that with increasing TIBA from $100 \mathrm{mM}$ to $200 \mathrm{mM}$ it is possible to obtain products with Mooney viscosity of $25 \mathrm{MU}$ and $\mathrm{Mw} \times 10^{3}=350 \pm 150 \mathrm{~g} / \mathrm{mol}$.

Certainly, to achieve the desired rheological value, it is necessary to use various concentrations of alkyl aluminum, so, by reducing the amount of TIBA from $25 \mathrm{mM}$ to $50 \mathrm{mM}$, it is possible to obtain molecular weights of $\mathrm{Mw} \times 10^{3}=$ $700 \pm 200 \mathrm{~g} / \mathrm{mol}$ and Mooney viscosity $\geq 60 \mathrm{MU}$.

3.3. Application of High cis-1,4-BR Compounds in Tire. In the manufacture of a radial tire, many components are involved such as different types of rubber, pigments, chemicals, fabric cord, and bead wire. The rubber or related polymers undergo 


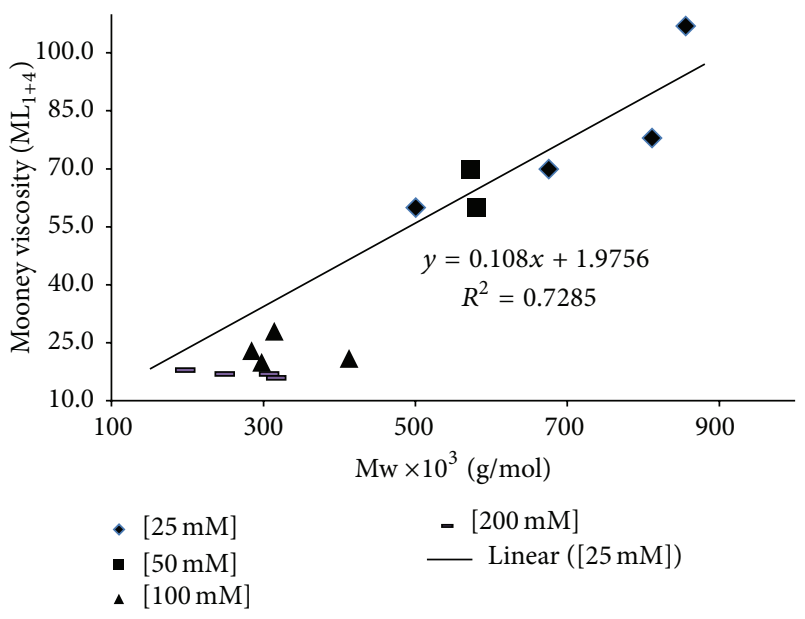

FIGURE 6: Mooney viscosity versus molecular weight of high cis-1,4BR.

TABLE 3: Basic formulation employed in the preparation of blends for tires.

\begin{tabular}{lc}
\hline Ingredients & Quantity/PHR \\
\hline Polymer & 100 \\
IRB 6 & 53.28 \\
Zinc oxide & 3.2 \\
Stearic acid & 1.07 \\
Sulfur & 1.86 \\
TBBS & 0.9 \\
\hline Total/g & 160.31 \\
\hline
\end{tabular}

a chemical process (vulcanizing) by the addition of sulfur and other compounds. The process begins with the mixing of "polymer" (of SBR or blend of SBR/PBD high cis-1,4-BR) with carbon black (IRB6), process oils (zinc oxide and stearic acid), cross-linking agents (sulfur) and primary accelerator to assist in the curing reaction (TBBS), pigments, and antioxidants. Table 3 shows the elements used to manufacture mixes, where different materials and the Mooney viscosities described were used. All these ingredients were combined in a Banbury type mixer under intense heat and pressure.

Table 4 shows the formulations of five blends of tires. One synthesized with n-BuLi SSBR (15\% styrene, 60\% vinyl) was used. Polybutadienes (high cis-1,4-BR) which used NdBR1 (98.3\% cis-1,4-BR, $30 \mathrm{MU})$, NdBR2 (98.0\% cis-1,4BR, 21.1 MU), and NdBR3 (97.6\% cis-1,4-BR, 61.1 MU) have a high content of 1,4-cis units and differentiate themselves from Mooney. Difficulty and slow addition of carbon black were observed during the preparation of the blends in the mixing chamber. This has already been reported [18] and can be attributed to the high molecular weight polybutadiene and low degree of branching. However, due to the increased mixing time, an improvement in the distribution of carbon black in the blend is expected.

In Table 5, the results indicate that the mechanical properties of the SBR containing compound are slightly modified by adding the high cis-1,4-BR. When higher Mooney viscosity
TABLE 4: Composition of blends for tires.

\begin{tabular}{lccccc}
\hline Composition/PHR & Blend $1^{\mathrm{a}}$ & Blend 2 & Blend $3^{\mathrm{b}}$ & Blend 4 & Blend 5 \\
\hline SBR & 34.308 & 22.300 & 19.899 & 22.300 & 22.300 \\
NdBR 1 & 0 & 12.008 & 14.409 & 0 & 0 \\
NdBR 2 & 0 & 0 & 0 & 12.008 & 0 \\
NdBR 3 & 0 & 0 & 0 & 0 & 12.008 \\
IRB 6 & 18.28 & 18.28 & 18.28 & 18.28 & 18.28 \\
Zinc oxide & 1.098 & 1.098 & 1.098 & 1.098 & 1.098 \\
Stearic acid & 0.367 & 0.367 & 0.367 & 0.367 & 0.367 \\
Sulfur & 0.638 & 0.638 & 0.638 & 0.638 & 0.638 \\
TBBS & 0.309 & 0.309 & 0.309 & 0.309 & 0.309 \\
\hline Total/g & 55.000 & 55.000 & 55.000 & 55.000 & 55.000 \\
\hline
\end{tabular}

${ }^{\mathrm{a}}$ Except for Blend 3, polybutadienes represent $35 \%$ by weight of the total polymer.

${ }^{\mathrm{b}}$ In Blend $342 \%$ was added by weight of polybutadiene to total of the polymer.

of cis-1,4-BR (Blend 5) is added, both the tensile strength and the elongation at break are maintained.

In other cases, except for Blend 3, containing a greater amount of high cis-1,4-BR, the tensile strength slightly decreases, while the elongation at break increases. Both results are to be expected, since the polybutadiene is more flexible but less rigid than the SBR. Furthermore, it can be observed that the rigidity of the blends decreases with Mooney viscosity, that is, with the molecular weight of high cis-1,4-BR. Blend 3 shows an interesting result in that the tensile strength tends to increase at higher rates than the other blends as elongation occurs. This could be attributed to the stress induced crystallization, as polybutadiene molecules, which are virtually free of defects, elongate and tend to be targeted better, which gives the blend better mechanical properties.

On the other hand, the abrasion resistance and the Tan delta at $0^{\circ} \mathrm{C}$ and $60^{\circ} \mathrm{C}$ (see Table 5), shown to evaluate the tire performance, have produced interesting results. Both factors are significantly decreased by combining the SBR with high cis-1,4-BR, due in part to the high stereochemical purity of polybutadiene (its $T_{q}$ is much less than that of SBR) and high linearity of its chains, which reflects its better elasticity. Additionally, the Tan delta notoriously decreases at both temperatures as the polybutadiene level increases. No significant effect between the types of polybutadiene used was observed, so, in principle, any high cis-1,4-BR with Mooney viscosity in the range of 20 to $60 \mathrm{MU}$ may advantageously be used to lower the Tan delta. As is known, small values of Tan delta at $0^{\circ} \mathrm{C}$ and $60^{\circ} \mathrm{C}$ result in a better wet grip and lower rolling resistance, respectively. This property indicates that the high cis-1,4-BR may be suitably used in manufacturing stronger, thinner, lighter weight tire walls, with lower rolling resistance. Another important factor to consider is resilience. In the data shown in Table 4, suitability has increased resilience in blends containing polybutadiene. Furthermore, the resilience appears to increase with the level of polybutadiene and gives the impression that it diminishes slightly with Mooney viscosity. Increased resilience or rebound can be related 
TABLE 5: Mechanical properties of SBR.

\begin{tabular}{|c|c|c|c|c|c|}
\hline Properties & Blend $1^{\mathrm{a}}$ & Blend 2 & Blend $3^{\mathrm{b}}$ & Blend 4 & Blend 5 \\
\hline Resilience at $25^{\circ} \mathrm{C} / \%$ & 26 & 46 & 49 & 41 & 44 \\
\hline Abrasion $/ \mathrm{mm}^{3}$ & 108.73 & 72.26 & 76.68 & 68.37 & 69.08 \\
\hline Hardness shore A-2 & 70 & 71 & 71 & 72 & 70 \\
\hline Tensile strength/MPa & 19.88 & 19.83 & 20.14 & 19.61 & 18.23 \\
\hline Elongation at break/\% & 359.6 & 350.1 & 341.8 & 376.5 & 371.8 \\
\hline Elongation modulus at $50 \% / \mathrm{MPa}$ & 2.50 & 2.35 & 2.42 & 2.37 & 2.39 \\
\hline Elongation modulus at $100 \%$ elongation $/ \mathrm{MPa}$ & 4.56 & 4.28 & 4.31 & 4.25 & 3.67 \\
\hline Elongation modulus at $300 \%$ elongation $/ \mathrm{MPa}$ & 16.87 & 16.36 & 17.07 & 15.37 & 14.32 \\
\hline Tan delta at $60^{\circ} \mathrm{C}$ & 0.123 & 0.104 & 0.0088 & 0.108 & 0.117 \\
\hline Tan delta at $0^{\circ} \mathrm{C}$ & 0.129 & 0.113 & 0.105 & 0.116 & 0.120 \\
\hline
\end{tabular}

${ }^{a}$ Except for Blend 3, polybutadienes represent $35 \%$ by weight of the total polymer.

${ }^{\mathrm{b}}$ In Blend $342 \%$ was added by weight of polybutadiene to total of the polymer.

to a reduction in the tire temperature, which makes the use of high cis-polybutadiene in formulations for flat tires particularly attractive. Factors such as rolling resistance, resilience, and grip in the wet have a significant importance in the manufacture of so-called green tires. These tires besides having an optimum balance of wet grip and wear have a lower rolling resistance, allowing for significant savings in fuel consumption.

\section{Conclusions}

The influence of the initial reaction temperature and the addition of alkyl aluminum play an important role in monomer conversion and polymer molecular weight. It is possible to achieve complete conversion of the monomer and low gel content when $\mathrm{NdV}_{3}$ is used as a catalyst. As the level of TIBA increases from 25 to $200 \mathrm{mM}$, the conversion increases and acts as a chain transfer agent decreasing the molecular weight, often generating new species. The increase in TIBA from 25 to $200 \mathrm{mM}$ results in a reduction in Mooney viscosity from 100 to $16 \mathrm{MU}$. To achieve the desired rheological value, it is necessary to increase the amount of TIBA from 25 to $50 \mathrm{mM}$ to obtain molecular weights of $\mathrm{Mw} \times 10^{3}=700 \pm$ $200 \mathrm{~g} / \mathrm{mol}$ and a Mooney viscosity $\geq 60 \mathrm{MU}$. The mechanical properties of the SBR containing compound are modified slightly by adding high cis-1,4-BR. By adding high cis-1,4BR with the higher Mooney viscosity (Blend 5), both tensile strength and elongation at break are maintained. The abrasion resistance and Tan delta at $0^{\circ} \mathrm{C}$ and $60^{\circ} \mathrm{C}$ are significantly decreased by combining the SBR with high cis-1,4-BR. The resilience increases with the level of high cis-1,4-BR and diminishes slightly with Mooney viscosity. The use of high cis-1,4-BR obtained with $\mathrm{NdV}_{3}$ in formulations for flat tires has significant importance in the manufacture of so-called green tires.

\section{Competing Interests}

The authors declare that there are no competing interests regarding the publication of this paper.

\section{Acknowledgments}

The authors would like to thank Dynasol Elastomers (Development Investigation Center) for financial assistance and to acknowledge Angel Ernesto García Avalos for help during the preparation of blends for tires and the testing of the same.

\section{References}

[1] L.-B. Wu, B.-G. Li, K. Cao, and B.-F. Li, "Styrene polymerization with ternary neodymium-based catalyst system: effects of catalyst preparation procedures," European Polymer Journal, vol. 37, no. 10, pp. 2105-2110, 2001.

[2] J. Wilson David and K. Jenkins Derek, "Butadiene polymerisation using ternary neodymium-based catalyst systems," Polymeri Bulletin, vol. 27, no. 4, pp. 407-411, 1992.

[3] X. Jia, Y. Hu, Q. Dai, J. Bi, C. Bai, and X. Zhang, "Synthesis of syndiotactic cis-1,4-polypentadiene by using ternary neodymium-based catalyst," Polymer, vol. 54, no. 12, pp. 29732978, 2013.

[4] D. K. Jenkins, "Butadiene polymerization with a rare earth compound using a magnesium alkyl cocatalyst: 2 ," Polymer, vol. 26, no. 1, pp. 152-158, 1985.

[5] G. Song, Z. Gu, P. Li, L. Wang, and L. Gao, "The properties of organo-montmorillonite/cis-1,4-polybutadiene rubber nanocomposites and the effect of recovered solvent on the conversion of butadiene polymerization," Applied Clay Science, vol. 65-66, pp. 158-161, 2012.

[6] M. Maiti, V. K. Srivastava, S. Shewale, R. V. Jasra, A. Chavda, and S. Modi, "Process parameter optimization through Design of Experiments in synthesis of high cis-polybutadiene rubber," Chemical Engineering Science, vol. 107, pp. 256-265, 2014.

[7] G. Kwag, P. Kim, S. Han, and H. Choi, "Ultra high cis polybutadiene by monomeric neodymium catalyst and its tensile and dynamic properties," Polymer, vol. 46, no. 11, pp. 3782-3788, 2005.

[8] C. Wang, "In situ cyclization modification in polymerization of butadiene by rare earth coordination catalyst," Materials Chemistry and Physics, vol. 89, no. 1, pp. 116-121, 2005.

[9] D. Gong, W. Dong, J. Hu, X. Zhang, and L. Jiang, "Living polymerization of 1,3-butadiene by a Ziegler-Natta type catalyst composed of iron(III) 2-ethylhexanoate, triisobutylaluminum 
and diethyl phosphite," Polymer, vol. 50, no. 13, pp. 2826-2829, 2009.

[10] F. M. B. Coutinho, T. C. J. Rocha, I. L. Mello, D. S. S. Nunes, B. G. Soares, and M. A. S. Costa, "Effect of electron donors on 1,3butadiene polymerization by a ziegler-natta catalyst based on neodymium," Journal of Applied Polymer Science, vol. 98, no. 6, pp. 2539-2543, 2005.

[11] S. Ramarad, M. Khalid, C. T. Ratnam, A. Luqman Chuah, and W. Rashmi, "Waste tire rubber in polymer blends: a review on the evolution, properties and future," Progress in Material Science, vol. 72, pp. 100-140, 2015.

[12] R. P. Quirk, A. M. Kells, K. Yunlu, and J.-P. Cuif, "Butadiene polymerization using neodymium versatate-based catalysts: catalyst optimization and effects of water and excess versatic acid," Polymer, vol. 41, no. 15, pp. 5903-5908, 2000.

[13] L. Mello Ivana and M. B. Coutinho Fernanda, "Neodymium Ziegler-Natta catalysts: evaluation of catalyst ageing effect on 1,3-butadiene polymerization," European Polymer Journal, vol. 44, no. 9, pp. 2893-2898, 2008.

[14] N. M. T. Pires, F. M. B. Coutinho, and M. A. S. Costa, "Synthesis and characterization of high cis-polybutadiene: influence of monomer concentration and reaction temperature," European Polymer Journal, vol. 40, no. 11, pp. 2599-2603, 2004.

[15] K. Gwanghoon, "A highly reactive and monomeric neodymium catalyst," Macromolecules, vol. 35, no. 13, pp. 4875-4879, 2002.

[16] O. Nuyken, Neodymium Based Ziegler Catalysts-Fundamental Chemistry, vol. 204 of Advances in Polymer Science, Springer, Berlin, Germany, 2006.

[17] A. V. Topchiev, B. A. Krentsel, and L. L. Stotskaya, "Organometallic complexes: olefine polymerisation catalysts," Russian Chemical Reviews, vol. 30, no. 4, pp. 192-207, 1961.

[18] V. D. Mochel, "NMR composition analysis of copolymers," Rubber Chemistry and Technology, vol. 40, no. 4, pp. 1200-1211, 1967.

[19] G. Sylvester and B. Stollfuss, "Process and catalyst for the preparation of syndiotactic 1,2-polybutadiene," in Proceedings of the 133rd Meeting of the American Chemical Society, p. 32, Dallas, Tex, USA, 1988.

[20] T. J. Woodman, Y. Sarazin, G. Fink, K. Hauschild, and M. Bochmann, "Heterogenized 'ligand-free' lanthanide catalysts for the homo- and copolymerization of ethylene and 1,3butadiene," Macromolecules, vol. 38, no. 8, pp. 3060-3067, 2005. 

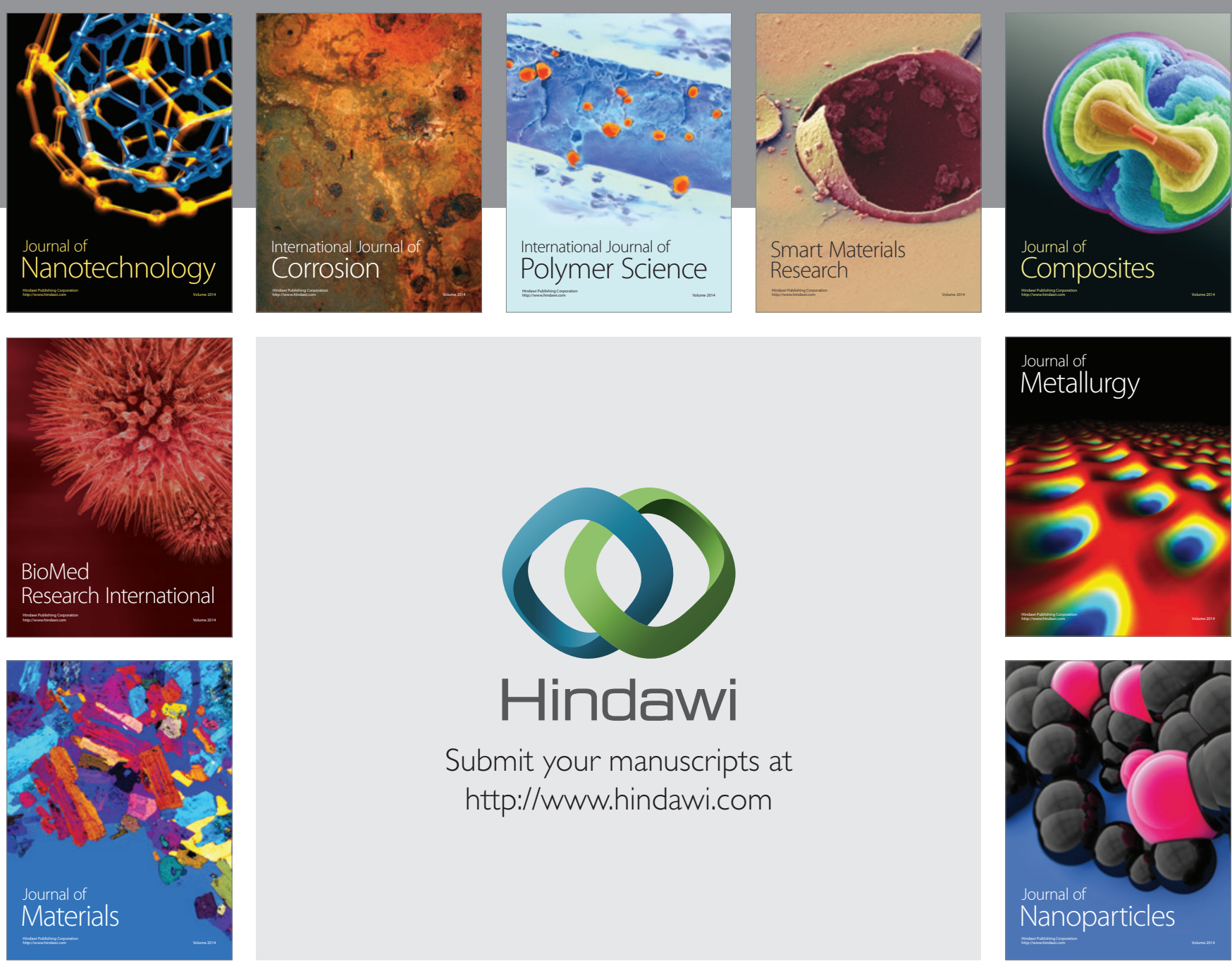

\section{Hindawi}

Submit your manuscripts at

http://www.hindawi.com

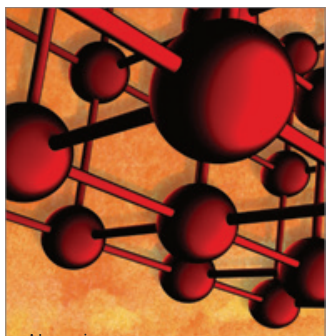

Materials Science and Engineering
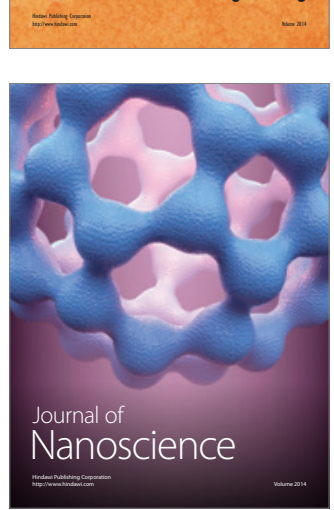
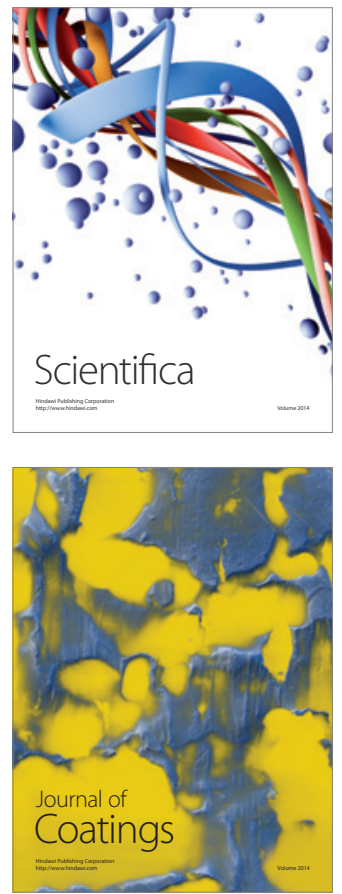
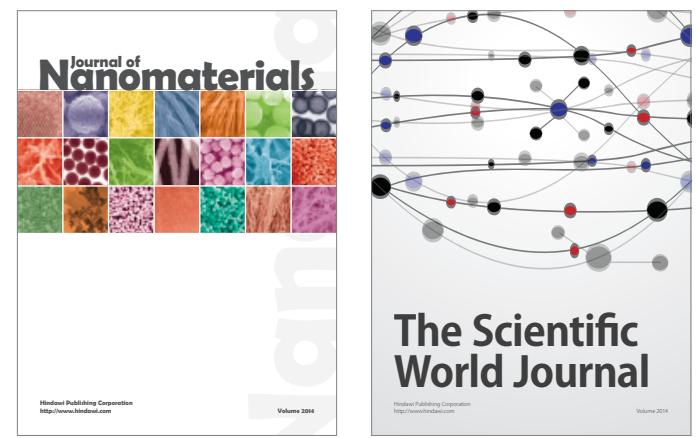

The Scientific World Journal
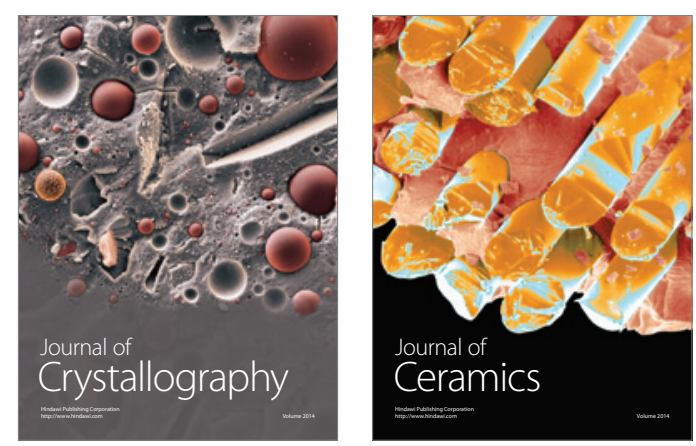
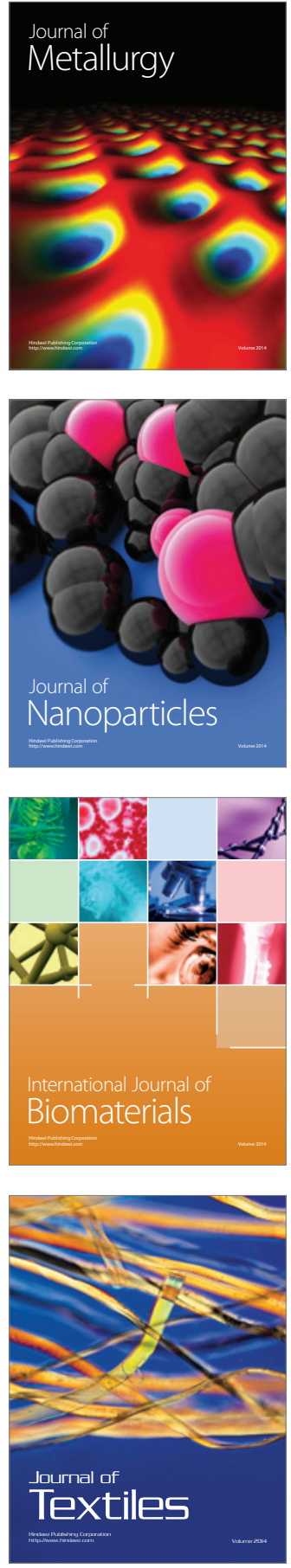